\title{
Iron speciation in coal fly ashes-chemical and Mössbauer analysis
}

\author{
T. Szumiata · K. Brzózka • B. Górka • M. Gawroński • \\ M. Gzik-Szumiata • R. Świetlik • M. Trojanowska
}

Published online: 13 November 2013

(C) Springer Science+Business Media Dordrecht 2013

\begin{abstract}
Iron speciation analysis of fly coal ashes was performed using transmision Mössbauer spectrometry as well as chemical methods. The investigated samples of ashes came from stoker-fired boiler and pulverized-fuel boiler (of significantly higher combustion temperature). The Mössbauer spectra show noticeable differences in iron-bearing phases content. In the first case aluminosilicate glass dominates, whereas in the second one-a spinel-type phase.
\end{abstract}

Keywords Fly ashes - Coal combustion · Mössbauer spectrometry · Chemical analysis · Iron speciation

\section{Introduction}

The application of Mössbauer spectrometry in the environmental protection studies is a very effective tool due to the high sensitivity of this method and precise phase analysis capabilities. Commonly, iron-based Mössbauer measurements are performed. They anable the determination of iron speciation in environmental polution products and the corelation of these data with content of heavy metals. Recently, Mössbauer spectrometry was successfully utilized in structural and magnetic properties analysis of fly ashes, fly ash-recycled glass, metallurgical slags as well as road dusts [1-4].

The main goal of this work is the investigation of combustion conditions influence (especially the combustion temperature) on iron speciation in coal fly ashes. This question is very

Proceedings of the 32nd International Conference on the Applications of the Mössbauer Effect (ICAME 2013) held in Opatija, Croatia, 1-6 September 2013

T. Szumiata $(\bowtie) \cdot$ K. Brzózka · B. Górka · M. Gawroński · M. Gzik-Szumiata

Department of Physics, University of Technology and Humanities in Radom,

Krasickiego 54, 26-600 Radom, Poland

e-mail: t.szumiata@uthrad.pl

R. Świetlik · M. Trojanowska

Department of Environmental Protection, University of Technology and Humanities in Radom, Chrobrego 27, 26-600 Radom, Poland 


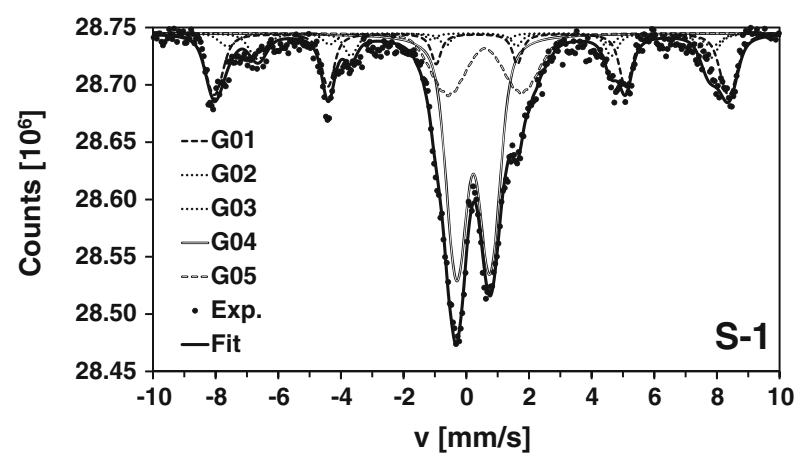

Fig. 1 Room temperature ${ }^{57} \mathrm{Fe}$ transmission Mössbauer spectrum for as-collected coal fly ash from stokerfired boiler in heating plant (sample 1)

Table 1 Hyperfine parameters for the Mössbauer spectrum of sample 1

\begin{tabular}{lllccllc}
\hline Comp. & $I S[\mathrm{~mm} / \mathrm{s}]$ & $\mathrm{SD}(I S)[\mathrm{mm} / \mathrm{s}]$ & $Q S[\mathrm{~mm} / \mathrm{s}]$ & $B[\mathrm{~T}]$ & $\mathrm{SD}(B)[\mathrm{T}]$ & $\gamma / 2[\mathrm{~mm} / \mathrm{s}]$ & $p[\%]$ \\
\hline $\mathrm{G} 01$ & 0.36 & 0 & -0.17 & 51.10 & 1.19 & 0.184 & 21.7 \\
$\mathrm{G} 02$ & 0.22 & 0 & 0.05 & 48.07 & 1.19 & 0.184 & 4.6 \\
$\mathrm{G} 03$ & 0.62 & 0 & 0.07 & 44.77 & 1.19 & 0.184 & 9.2 \\
$\mathrm{G} 04$ & 0.33 & 0.22 & 1.06 & 0 & 0 & 0.184 & 46.0 \\
$\mathrm{G} 05$ & 0.70 & 0.59 & 2.34 & 0 & 0 & 0.184 & 18.4 \\
\hline
\end{tabular}

important from the environmental protection point of view due to the huge amount of generated fly ashes (e.g. $15 \mathrm{Tg} /$ year in United Kingdom and $4 \mathrm{Tg} / \mathrm{year}$ in Poland). Such ashes are introduced into the environment during the utilization process (road construction as well as land reclamation and restoration).

\section{Experimental}

The object of the investigations were fly ashes generated in stoker-fired boiler (sample 1) or pulverized-fuel boiler (sample 2) operated in heating plant and power plant, respectively. In the first case a flue gas temperature is maintained at $750-800^{\circ} \mathrm{C}$, whereas in the second one-at about $1800-1900{ }^{\circ} \mathrm{C}$. The investigated fly ash samples were collected from dust collection device. The chemical analysis has revealed that the samples differ in iron content, significantly (sample 1: $48.9 \mathrm{~g} / \mathrm{kg}$, sample 2: $17.0 \mathrm{~g} / \mathrm{kg}$ ). Chemical fractionation of iron was carried out according to the modified Tessier's extraction scheme [5]. The iron concentrations in the eluates were determined by means of flame atomic absorption analyzer (F-AAS - Agilent Technologies 200 Series AA 240 FS AA of instrumental determination limit below $3.8 \mathrm{mg} / \mathrm{kg}$ ).

In order to determine the speciation of iron the standard ${ }^{57} \mathrm{Fe}$ Mössbauer spectrometry has been applied in vertical geometry at room temperature. The spectrometer was operating in constant acceleration mode utilizing 1024 time-resolved channels. The obtained Mössbauer spectra have been analyzed with dedicated PolMöss multithread package based 


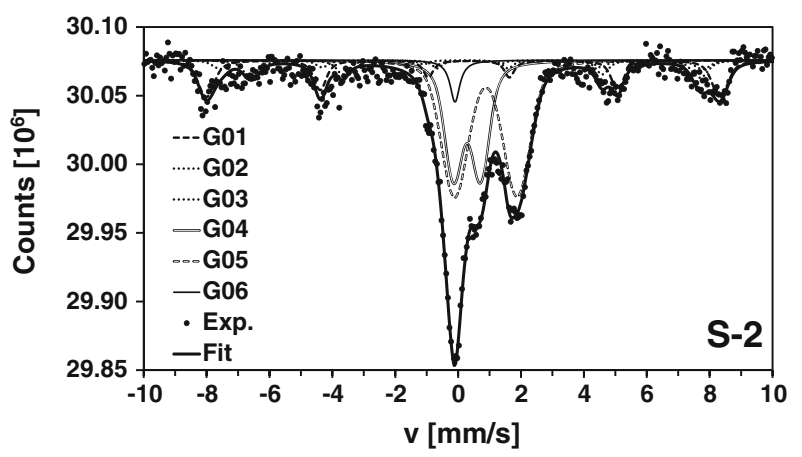

Fig. 2 Room temperature ${ }^{57} \mathrm{Fe}$ transmission Mössbauer spectrum for as-collected coal fly ash from pulverized-fuel boiler in power plant (sample 2)

Table 2 Hyperfine parameters for the Mössbauer spectrum of sample 2

\begin{tabular}{llllllll}
\hline Comp. & $I S[\mathrm{~mm} / \mathrm{s}]$ & $\mathrm{SD}(I S)[\mathrm{mm} / \mathrm{s}]$ & $Q S[\mathrm{~mm} / \mathrm{s}]$ & $B[\mathrm{~T}]$ & $\mathrm{SD}(B)[\mathrm{T}]$ & $\gamma / 2[\mathrm{~mm} / \mathrm{s}]$ & $p[\%]$ \\
\hline $\mathrm{G} 01$ & 0.36 & 0.00 & -0.18 & 50.86 & 1.04 & 0.188 & 15.9 \\
G02 & 0.22 & 0.00 & 0.00 & 47.70 & 1.04 & 0.188 & 3.8 \\
G03 & 0.62 & 0.00 & 0.10 & 44.40 & 1.04 & 0.188 & 7.6 \\
G04 & 0.39 & 0.24 & 0.86 & 0 & 0 & 0.188 & 26.9 \\
G05 & 0.99 & 0.34 & 1.99 & 0 & 0 & 0.188 & 42.7 \\
G06 & 0.01 & 0.03 & 0 & 0 & 0 & 0.188 & 3.2 \\
\hline
\end{tabular}

on MS Excel with Solver component for gradient-evolutionary optimization. PolMöss software was developed and successfully applied for the first time in order to process Mössbauer spectra of thin-layered Fe-Ga system [6, 7].

\section{Results and discussion}

The Mössbauer spectrum collected for the sample 1 is presented in Fig. 1. It has been fitted with five components assuming a Gaussian distribution of hyperfine parameters (Voigt method). The values of fitting parameters (isomer shift $I S$ related to $\alpha \mathrm{Fe}$, quadrupole splitting $Q S$, magnetic hyperfine $B$ and contribution $p$ of iron) derived for the sample 1 are listed in Table 1. The table presents also standard deviations (SD) which can be interpreted as half-widths of hyperfine parameters distributions. The first three high-field components (represented by Zeeman sextets) correspond to the iron oxides: hematite-G01 and magnetite, i.e. $\mathrm{G} 02\left(\mathrm{Fe}^{3+}\right)+\mathrm{G} 03\left(\mathrm{Fe}^{2.5+}\right)$ of $\mathrm{G} 03 / \mathrm{G} 02=2$ contribution ratio. The contribution of iron coming from these two phases is approximately $35.5 \%$ (relatively to all phases containing iron). The dominating G04 paramagnetic component (46.0\%) is a doublet of the values of $I S$ and $Q S$ pointing to $\mathrm{Fe}^{3+}$ origin - characteristic of iron-bearing paramagnetic aluminosilicate glass [8] identified as mullite (porcelanite, $\mathrm{Al}_{6} \mathrm{Si}_{2} \mathrm{O}_{13}$ ) with $\mathrm{Fe}^{3+}$ ions $[9,10]$. The last component G05 (doublet of $18.4 \%$ abundance) parameters correspond to fly ash paramagnetic phase with $\mathrm{Fe}^{2+}$ ions recognized in $[9,10]$ as hercynite $\left(\mathrm{Fe}^{2+} \mathrm{Al}_{2} \mathrm{O}_{4}\right.$ spinel). The widths of $I S$ distributions both for paramagnetic components are 
almost as huge as mean values, which is a sign of possible structural distortions, surface effects or chemical disorder. The 3:2:1 ration of line intensities of Zeeman sextets in the Mössbauer spectrum is typical for powder material with no magnetic nor polycrystalline texture. The value of half-width $\gamma / 2$ of base Lorentzian profile for all lines in all Zeeman sextets was adjusted numerically at the level assuring the smooth distributions of hyperfine parameters.

The sequential extraction procedure allowed to classify the total iron content in fly ash into six chemical fractions: (1) water leaching fraction $-0.0 \%$, (2) slightly acid-soluble fraction $-0.7 \%$, (3) reducible fraction $-6.7 \%$, (4) oxidizable fraction $-0.8 \%$, (5) environmentally persistent fraction $-35.2 \%$, and (5) residual fraction $-56.6 \%$. The fraction (3) of iron can be likely assigned to goethite and/or magnetite, whereas fraction (5) is probable an iron oxide surrounded by the coating of a moderate chemical resistance [11]. The residual fraction (6) is usually considered as a metal in the melted silicate or aluminosilicate phase. This fraction of iron can be identified as iron-bearing paramagnetic silicate glass phase (labeled as G04 component in the Mössbauer spectrum).

The main difference of the Mössbauer spectrum in Fig. 2. collected for the sample 2 (comparing to the sample 1) manifests itself in domination of the glass phase with $\mathrm{Fe}^{2+}$ in fly ash (Table 2, component G05), which could be directly related to significantly higher combustion temperature in a pulverized-fuel boiler than in a stoker-fired one. The similar trend in $\mathrm{Fe}^{2+}$ and $\mathrm{Fe}^{3+}$ abounded phases contributions is reported in [2], where the high temperature annealing process of ash-recycled glass was analyzed. Probable morphological form of the phase corresponding to G05 component are cenospheres or microspheres [8]. The content of hematite is lower in the second sample. Moreover, the spectrum contains a singlet (3.2\%) of near zero isomer shift (component G06) - possibly corresponding to superparamagnetic iron nanoparticles (also detected e.g. in road dusts [4]).

\section{Conclusions}

The speciation of iron in the investigated fly coal ashes reveals noticeable dependence on the combustion temperature. The most important difference is visible in the contributions of two paramagnetic glass-type phases of significantly different values of the isomer shift and quadrupole splitting (reported, but no well recognized in the literature). Qualitative consistency of Mössbauer spectrometry outcomes and chemical analysis allows to construct a future project of the comprehensive investigations of the iron speciation in fly coal ashes coming from different kinds of industrial combustion processes.

\section{References}

1. Bajukova, O.A., Anshits, N.N., Petrova, M.I., Balaev, A.D., Anshits, A.G.: Mater. Chem. Phys. 114, 495-503 (2009)

2. Nishida, T., Tokunaga, M., Sugata, Y., Kubuki, S.: J. Radioanal. Nucl. Chem. 266, 171-177 (2005)

3. Jończy, I., Stanek, J.: Nukleonika 58, 127-131 (2013)

4. Szumiata, T., Gawroński, M., Górka, B., Brzózka, K., Świetlik, R., Trojanowska, M., Strzelecka, M.: Nukleonika 58, 107-110 (2013)

5. Tessier, A., Campbell, P.G.C., Bisson, M.: Anal. Chem. 7, 844-851 (1979)

6. Szumiata, T., Górka, B., Brzózka, K., Gawroński, M., Gzik-Szumiata, M., Javed, A., Morley, N.A., Gibbs, M.R.J.: Nukleonika 58, 27-30 (2013) 
7. Javed, A., Szumiata, T., Morley, N.A., Gibbs, M.R.J.: Acta Materialia 58, 4003-4011 (2010)

8. Zyryanov, V.V., Petrov, S.A., Matvienko, A.A.: Fuel 90, 486-492 (2011)

9. Vandenberghe, R.E., de Resende, V.G., da Costa, G.M., De Grave, E.: Fuel 89, 2405-2410 (2010)

10. Vandenberghe, R.E., de Resende, V.G., De Grave, E.: Hyperfine Interact. 191, 11-16 (2009)

11. Świetlik, R., Trojanowska, M., Jóżwiak, M.A.: Fuel Process. Technol. 95, 109-118 (2012) 